Fifth International Conference on Sustainable Construction Materials and

Technologies. http://www.claisse.info/Proceedings.htm

\title{
MECHANICAL BEHAVIOR OF NATURAL FIBER TEXTILE REINFORCED MORTAR SHEETS
}

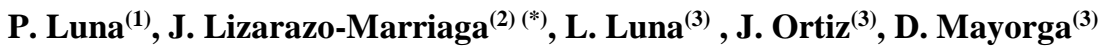 \\ (1) MSc., PhD Student, Universidad Nacional de Colombia, Engineering Faculty, Bogotá, Colombia. \\ plunat@unal.edu.co \\ (2) PhD. Prof., Universidad Nacional de Colombia, Engineering Faculty, Bogotá, Colombia. \\ jmlizarazom@unal.edu.co \\ (3) Research student, Universidad Nacional de Colombia, Engineering Faculty, Bogotá, Colombia. \\ rllunap@unal.edu.co \\ jodortizco@unal.edu.co \\ dcmayorgab@unal.edu.co \\ (*) corresponding author
}

\begin{abstract}
This paper summarizes preliminary results of an experimental research project aimed to develop natural fiber textile-reinforced mortars (NFTRM) to be used in the construction industry. Here, the bending behavior of mortar sheets reinforced using fique textiles was analyzed. In order to assess the influence of a textile grid on the bending behavior of mortar sheets, two different fique fabrics were used to cast square plates. Their mechanical bending behavior strength were also compared with mortar sheets reinforced using commercial fibers. Results showed that fique fabrics are a promising substitute for commercial fibers because they provide the material with an adequate flexural behavior, showing a remarkable increase in ductility and the capacity to store energy after cracking.
\end{abstract}

Keywords: Fique; natural fibers; cement-based composites;

\section{INTRODUCTION}

Composite materials reinforced using synthetic fibers such as glass or carbon have been applied during the last 50 years in all industrial sectors such as transport (aeronautics, automotive, and naval), sporting goods and construction. Composites are stronger than other materials, light in weight, resist damage from weather and some chemicals, have a long life and require little maintenance. Synthetic fibers are mainly obtained from synthesized polymers, whose raw materials come from petroleum-based petrochemicals. Because of the synthetic fibers' dependence on oil, in the last few years, the composite materials industry has turned towards natural fibers. As a result, the scientific community has also turned towards natural fibers such as abaca, jute, sisal [1], cotton, flax, palf, hemp, and ramie [2], among others. In the same way, a lot of 
research have been carried out on polymeric matrices for natural fibers (such as epoxy, polyester, vinyl-ester, phenolic polymers [3]), and in cement-based matrices [4].

Although there are reports on natural fibers showing some weaknesses such as lower strength, variable quality, limited moisture resistance which causes fiber swelling, restricted maximum processing temperature, lower durability depending on the matrix, poor fire resistance, poor fiber/matrix adhesion and price fluctuation by harvest results or agricultural politics [5], it is increasingly common nowadays to find composites using natural fibers in the most diverse applications. Natural fibers are a clear example of recyclability, renewability and biodegradability, and additionally supply thermal and acoustic insulation, and structural lightness [6]. The performance of a composite depends on the type of fiber employed, so it is necessary to analyze each of them in a particular way.

In the Andean region of South America, Fique is one of the most abundant fibers, which is used for the manufacture of handicrafts and bags and packages for agriculture [6]. According to S.A. Ovalle-Serrano et al. [7], Colombia is the largest producer of Fique fibers in the world, having more than 30,000 tons per year. Fique belongs to the group of hard fibers, often referred to as cabuya (Furcrae gender), and it is extracted from the leaves of the fique plant, a group of xerophytic monocotylic plants [8]. According to Gañán and Mondragón [9], fique fibers are composed of cellulose $(63.0 \%)$, hemicellulose $(17.5 \%)$, lignin $(14.5 \%)$, pectins and waxes $(5.0 \%)$, and the fiber length typically ranges between 80 and $100 \mathrm{~cm}$.

As natural fique fibers are obtained from renewable sources and are available at very low cost compared to synthetic fibers, research have been carried out developing applications for new construction products. Delvasto et al. [10], by using fique fibers, produced corrugated roof cement sheets manufactured through a vacuum forming method. Tonoli et al. [11] reported cement roof tiles reinforced using fique fibers, and Hidalgo-Salazar and Correa [6] reported the incorporation of fique fiber mats on polymer matrices.

This paper summarizes some preliminary results of an experimental research project aimed to develop natural fiber textile-reinforced mortars (NFTRM) to be used in the construction industry. Here, the bending behavior of mortar sheets reinforced using two fique textile directions was researched. In order to assess the influence of a textile grid on the bending behavior of mortar sheets, two different fique fabrics were used to cast square plates. Their mechanical behavior and bending strength were also compared with mortar sheets reinforced using commercial fibers. As durability is a concern in the field of cement-based composites because the alkaline pore solution weakens natural fibers, a partial substitution of cement using silica fume was employed in this project, in order to reduce the mortar alkalinity through the pozzolanic reaction. However, the long-term durability performance of fique composites was not shown in this paper.

\section{EXPERIMENTAL PROGRAM}


Experiments consisted mainly of bending tests of composite specimens, consisting of fique textiles embedded in mortar matrices. A detailed description of the materials and experiments carried out are summarized below.

\section{Materials and Mix Design}

Composite matrices were prepared from mortar using natural sand with a standard ASTM C33 grading. The natural aggregate was mainly siliceous holding a $98 \% \mathrm{SiO}_{2}$ content. Figure 1 shows the sand particle size distribution. Physical properties of aggregates were the apparent specific gravity: 2.63 , the loose bulk density $(\mathrm{g} / \mathrm{cm} 3)$ : 1.64 and the effective absorption (\%): 2.8. Aggregates were mixed under oven dry conditions.

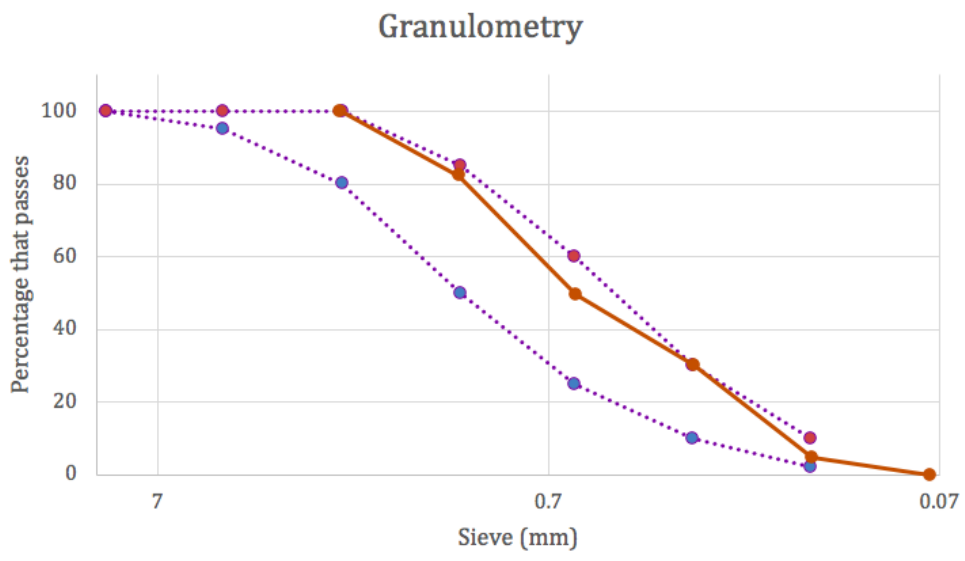

Figure 1. Sand particle size distribution of mortar matrix

Commercial hydraulic ASTM C1157 cement, classified for general use (GU type) according to the producer was employed. The specific gravity of cement was 2.96 , and the fineness obtained from the Blaine method was $4804 \mathrm{~cm}^{2} / \mathrm{g}$. The chemical characterization of cement obtained from the XRF in terms of oxides is shown in Table 1 .

Table 1. Chemical oxide composition of binders used

\begin{tabular}{|c|c|}
\hline Compound & \% by weight \\
\hline $\mathrm{CaO}$ & 68.16 \\
\hline $\mathrm{SiO}_{2}$ & 16.29 \\
\hline $\mathrm{SO}_{3}$ & 5.46 \\
\hline $\mathrm{Fe}_{2} \mathrm{O}_{3}$ & 3.55 \\
\hline $\mathrm{Al}_{2} \mathrm{O}_{3}$ & 3.38 \\
\hline $\mathrm{MgO}$ & 1.98 \\
\hline $\mathrm{TiO}_{2}$ & 0.43 \\
\hline $\mathrm{K}_{2} \mathrm{O}$ & 0.36 \\
\hline $\mathrm{Na}_{2} \mathrm{O}$ & 0.19 \\
\hline
\end{tabular}


For all mortar mixtures a constant 1:2.75 cement to aggregate ratio was used, and they had a water to cement ratio of 0.43 . Because of the low water to cement ratio, a polycarboxylate superplasticizer was used in order to ensure the correct workability of mortar mixtures during the composite fabrication. The dose of the superplasticizer was previously determined in such a way that the fluidity of the mixtures was maintained in the range of $110 \% \pm 5 \%$ according the NTC 111. After casting, composite specimens were water cured until tests, and three composite specimens were fabricated for each test conditions.

Fique sacks used to store agricultural products were used as a textile natural fiber by varying the spacing between the fibers of the fique grid. Two different types of meshes were used as mortar reinforcement. A very dense mat with a spacing between fibers of around $0.2 \mathrm{~mm}$ and another standard mat with a fiber spacing of around $2.5 \mathrm{~mm}$. Figures 2 shows a single fique fiber and a close up of the mats used in this research. The color varies between one grid and another because they come from different factories.

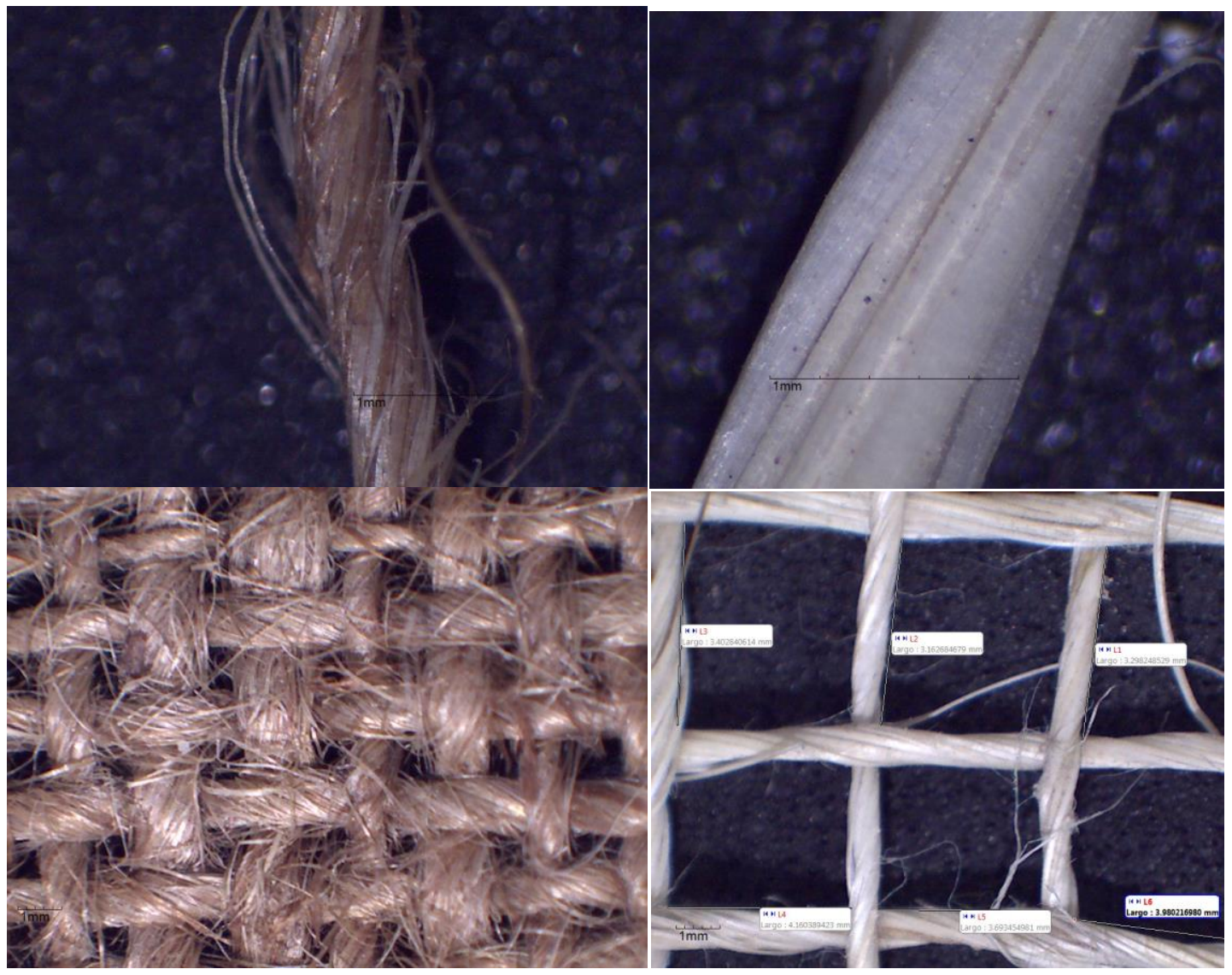

Figure 2. Left: dense mat; and Right: standard mat. Spacing between fibers of around 0.2 and $2.5 \mathrm{~mm}$

Commercial polypropylene/polyethylene synthetic macro-fibers were used to be compared with the fique textiles because this fiber have a flexural behavior already 
measured and serves as a frame of reference. Synthetic fibers comply with ASTM C1116 (Standard Specification for Fiber Reinforced Concrete), in which they are reported to improve concrete's tensile and bending strength. A dosage of $3.0 \mathrm{~kg} / \mathrm{m}^{3}$ was used in this research.

\section{Composite Fabrication}

Fique textile reinforced mortar sheets were manufactured using wooden moulds with dimensions of 600x600 mm and a thickness of 30mm. After mixing the mortar matrix, the molds were filled with mortar approximately up to half of their height and shaken manually for 30 seconds. Then, the textile previously saturated using lime water was placed in the middle of the specimen, and a second layer of mortar was cast. Finally, the mold was completely filled and shaken again. In order to avoid compaction variations which might have affected the matrix, specimens were all compacted to a maximum density. Figure 4 shows a schematic representation of a fique sheet.

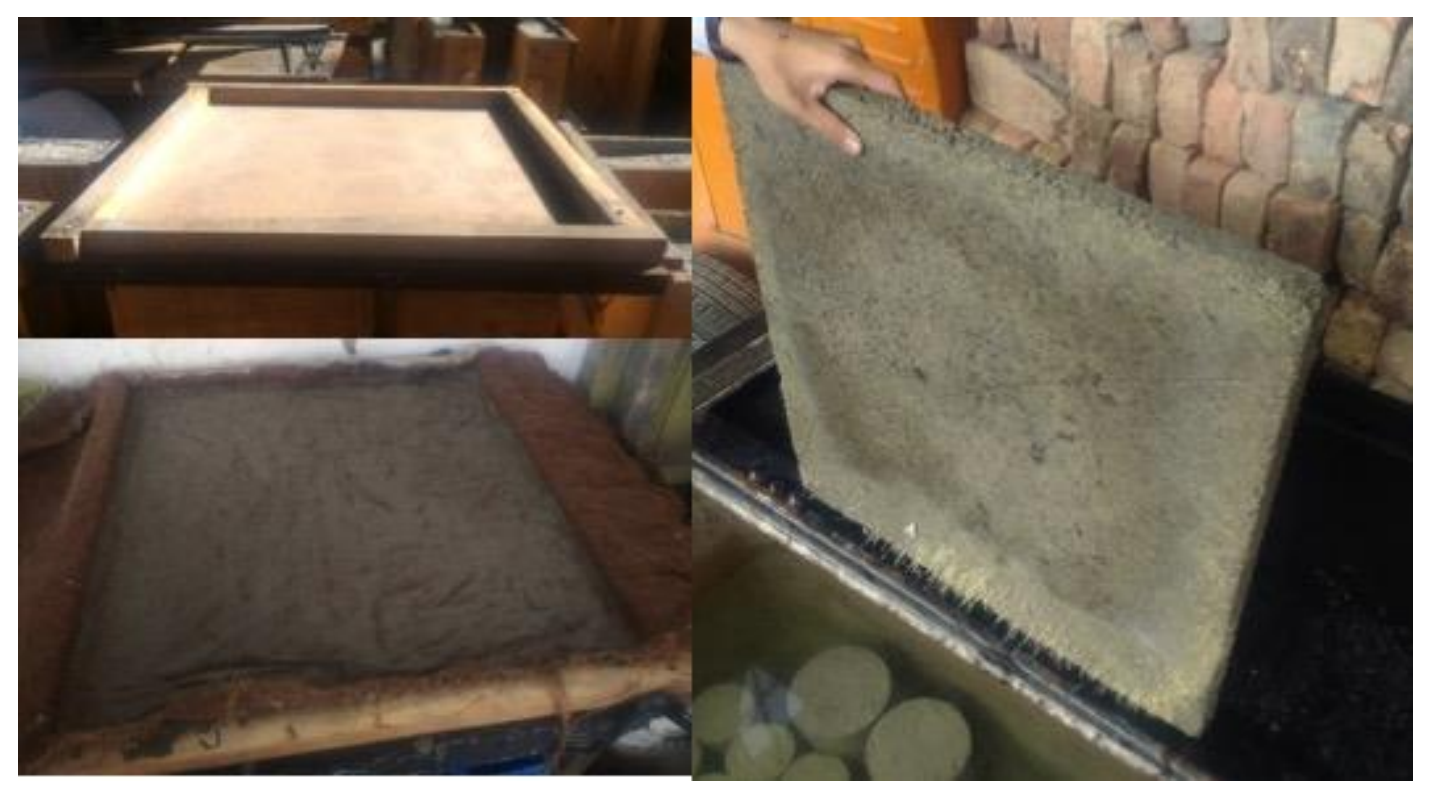

Figure 3. Fique composite manufacturing

The procedure for the sheets using polypropylene fibers was different because the fibers were mixed together with the mortar. After demoulding, the composite specimens were also kept in water containers at $20 \pm 2{ }^{\circ} \mathrm{C}$.

\section{Experiments}

Tests were carried out in order to determine the bending behavior of the fique reinforced sheets. Three specimens were tested for each condition. The mortar sheets of $600 \times 600 \times 30 \mathrm{~mm}$ were held by its 4 edges in a metallic frame and a center point load was applied through a contact surface of $100 \times 100 \mathrm{~mm}$. The test span was set to $500 \mathrm{~mm}$ for all the specimens. The rough side was on the bottom during the test and the deflection rate of the midpoint was set around $1.5 \mathrm{~mm}$ per minute. The composite bending test was carried out using a hydraulic jack coupled in the rigid metallic frame. 
Deflections were measured on the mid part of the plate and on the border as shown in Figure 5. Tests were carried out controlling the load before the initial cracking of the specimen, and controlling the deflection after that initial cracking condition appeared.

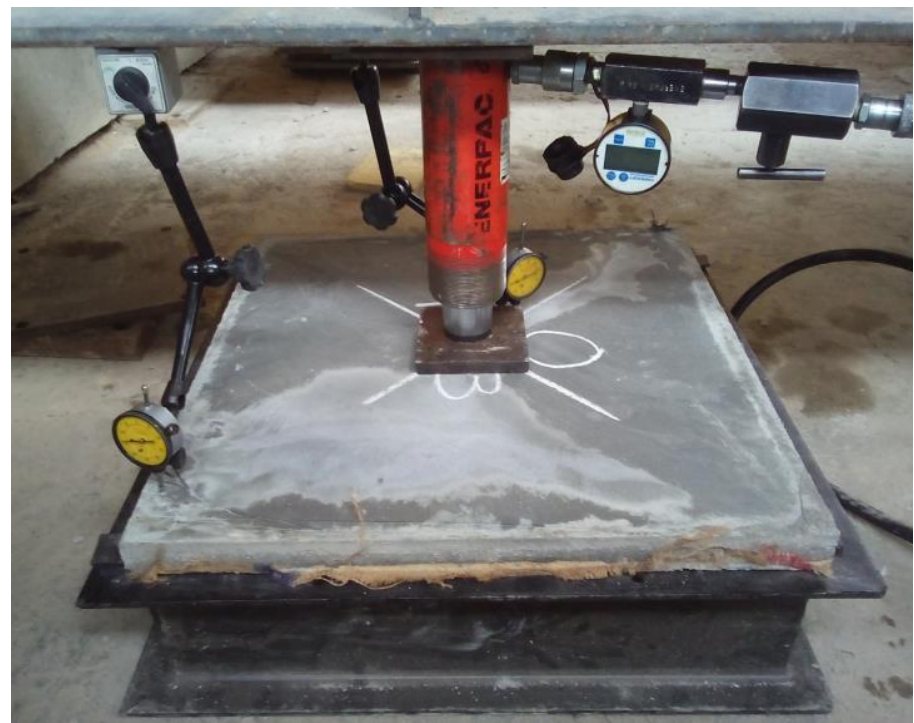

Figure 4. Experimental setup of the plate bending test

\section{RESULTS AND DISCUSSION}

Bending test results for mortar sheets without any kind of reinforcement are shown in Figure 5. Specimens are considered as a reference because no fibers were used, in such a way that the behavior of the sheets was totally fragile. As expected during the whole test, the material maintained an elastic behavior, in which, after the appearance of the first crack, the failure of the sheet occurred immediately. The recorded deflections are considered to be very low and the capacity of the sheet to dissipate energy in the inelastic range of deformations was very low.

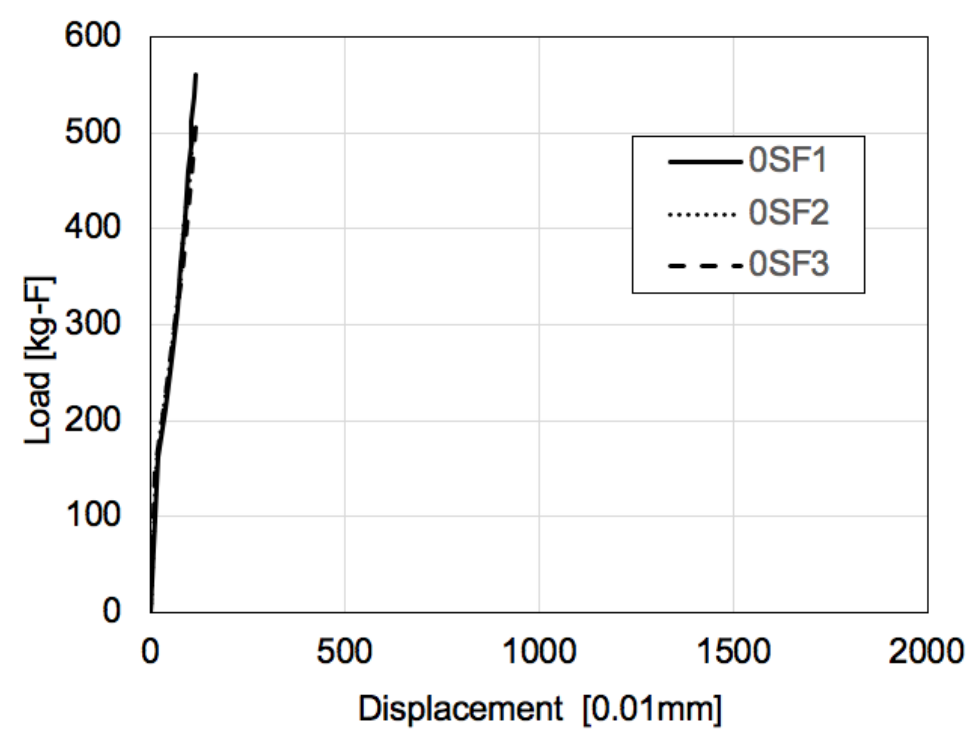


Figure 5. Bending behavior of sheets without reinforcement

Bending results for composites reinforced using a dense mat (spacing between fibers of around $0.2 \mathrm{~mm}$ ) are shown in Figure 6. Unlike the specimen without reinforcement, high levels of mortar cracking were obtained after the initial elastic response. The stress measured during the first crack corresponds to the mortar's tensile strength (rupture modulus), and it is in the same range as that of the sheet without reinforcement. As reported by Kouris and Triantafillou [12], the number and the form of cracks after the peak load reached depend on the grid spacing of the textile and the interlocking behavior of the grid and the mortar matrix. In the same way, a loss of stiffness caused by the development of cracks is observed, although the plate maintains the load through large deformations, showing a ductile behavior.

As was stated before, the sheet bending behavior after the peak load depends on the quality of the bond between fique textile and mortar matrix. Figure 6 shows that the dense fique mat (spacing between fibers of around $0.2 \mathrm{~mm}$ ) has numerous fluctuations on the force-deflection curve. The numerous peaks observed are attributed to the ability of the textile to develop a bonding stress, which is exhausted at some time, but quickly recovered.

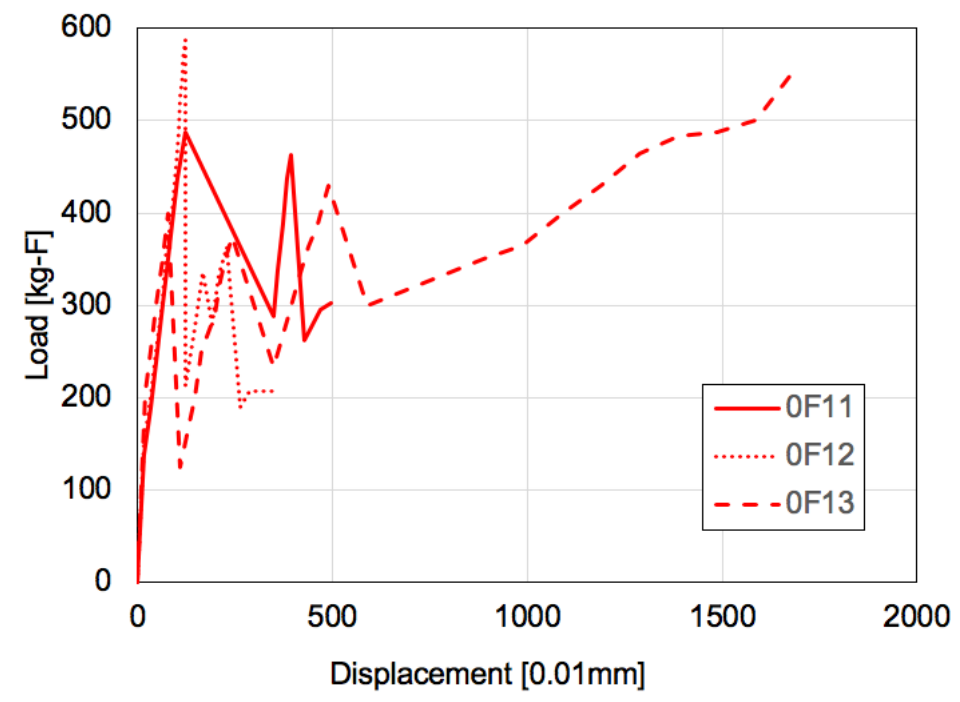

Figure 6. Bending behavior of dense natural fiber sheets

The bond between the mortar matrix and the reinforcement textile fique fibers is of high importance for the bending behavior of the composite sheets. Dense fique textiles showed a limited ductility because there was a minimum interlocking. As the separation of the fibers was very small, the mortar did not penetrate between them, decreasing their anchoring capacity. The previous situation promoted some debonding, which lead to premature failure and to limited activation of fibers. Similar results were 
reported by Kouris and Triantafillou [12]. Figure 7 shows a close up of the fiber and matrix bonding. There can be seen that the fibers were close enough not to allow the mortar to penetrate between them. Taking into account that the bonding stress is characterized by a friction and an interlocking part between fibers and matrix, for this condition this last term is considered minimal.

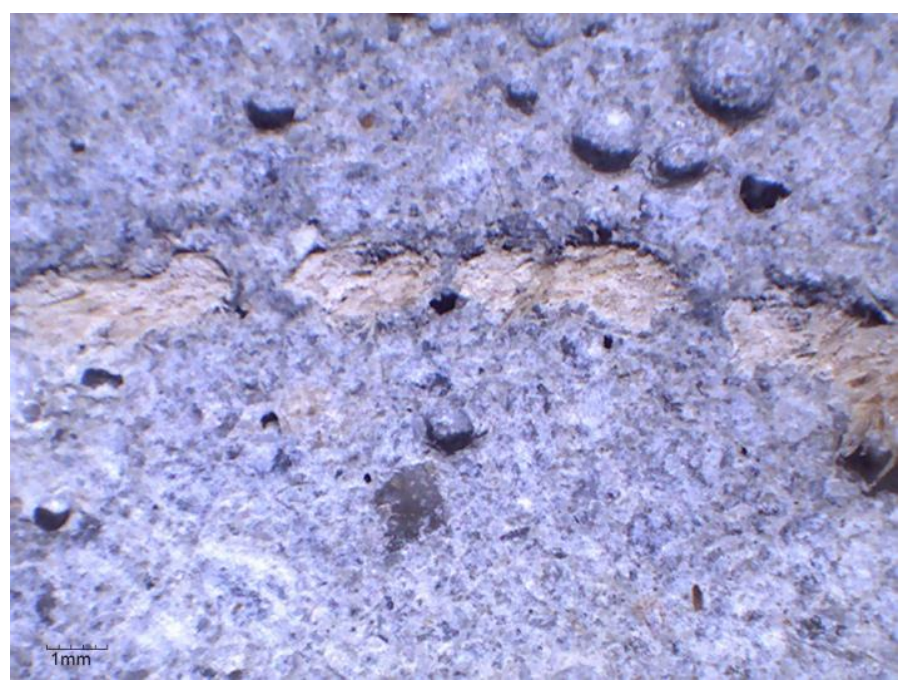

Figure 7. Detail of dense fique textile embedded into the mortar matrix

Bending results for composites reinforced using a standard mat (spacing between fibers of around 2,5 mm) are shown in Figure 8. The first crack was in the same load range as that of the reference composite specimen. This was expected since the rupture modulus is mainly a function of the mechanical properties of the mortar matrix. The three specimens tested are plotted in the figure. As expected in the field of natural fibers, there was an important variability among the specimens, although the general behavior showed a good trend. Unlike the dense fiber sheets reinforcement, a significant number of peaks occurred throughout the entire test, not only in the initial part of the experiment. This shows that the bonding stress, dominated by the interlocking, controls the test in its non-linear portion. 


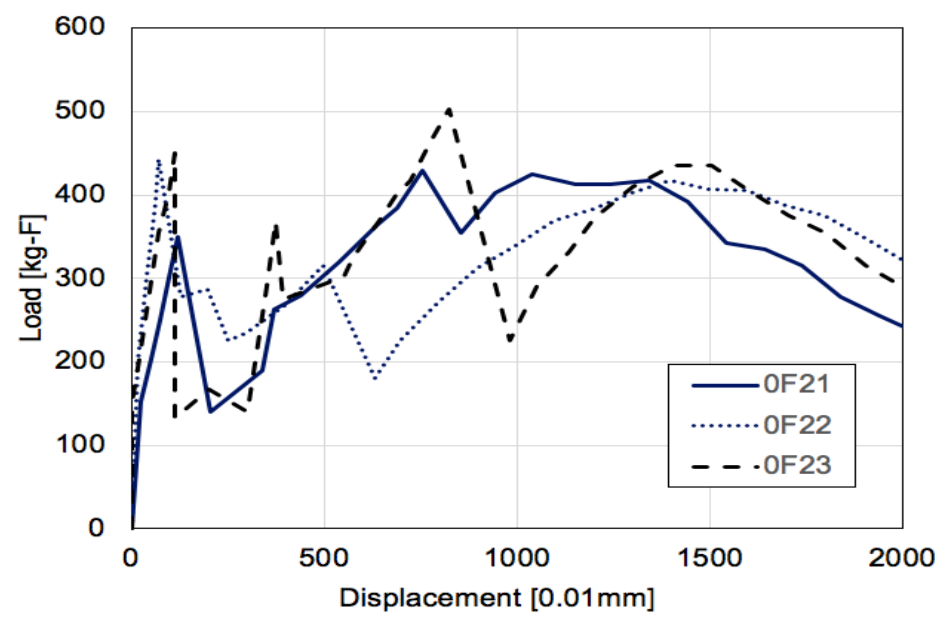

Figure 8. Bending behavior of standard natural fiber sheets

Although important load oscillations are observed in the non-linear zone after the first crack, the following observations can be presented: i) the composite shows a ductile behavior with large deformations; ii) Although load variations are important, the average value obtained for the three specimens remains adequate; iii) the fibers work throughout the whole test maintaining the average load, but presenting oscillations relative to the variation of the adhesion forces. Figure 9 shows a close up of the fiber and matrix bonding for the standard fique textile. There can be seen that the fibers were sufficiently spaced to allow the mortar to penetrate between them, thus generating the interlocking component of the bonding.

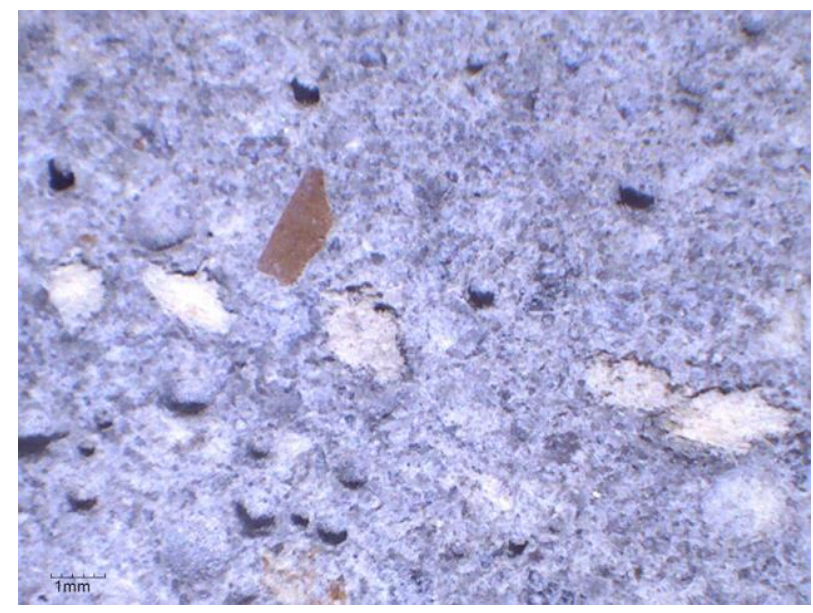

Figure 9. Detail of the standard fique textile embedded in the mortar matrix

Results of synthetic polypropylene fiber sheets are shown in Figure 10. A ductile behavior of the composites is observed, with some initial post peak fluctuations in the zone of low deflections, followed by a well-defined behavior, with a softening and little oscillating force-displacement curve. 


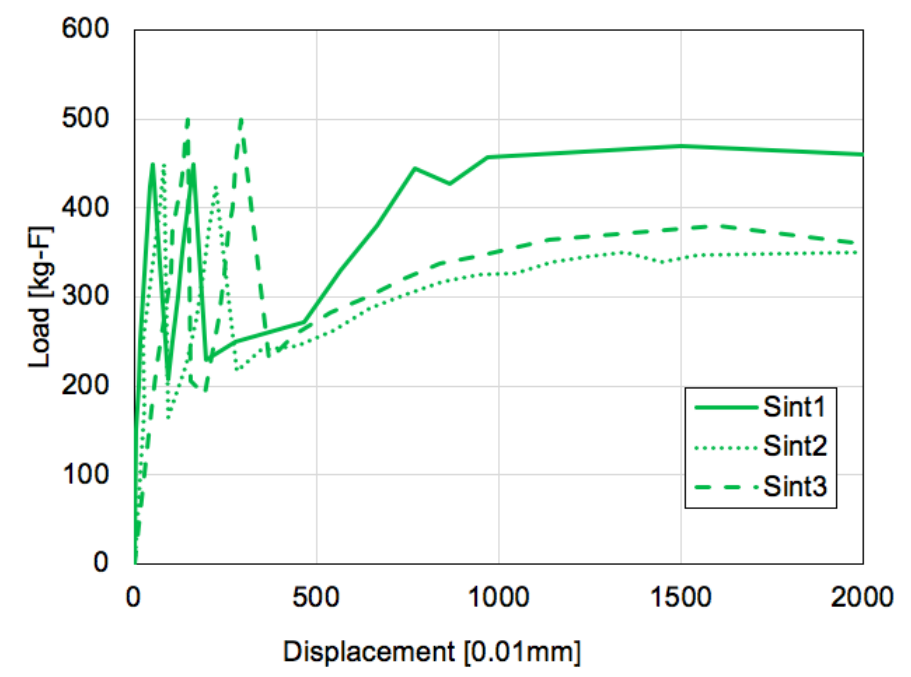

Figure 10. Bending behavior of synthetic polypropylene fiber

Taking into account that the contribution of fibers is improving the ductility and the behavior after the cracking of the composite, the final pattern of cracking is shown in Figure 11. Photo A shows how the reference sample with no reinforcement failed completely after the test and was fragmented into several portions. The specimens exhibit no ductility. Photo B shows the cracking pattern for the dense fiber sheets. Diagonal cracks were formed, and the specimen was held together by the textile once the matrix lost all rigidity. Photo $\mathrm{C}$ shows the cracking pattern for the standard fiber sheets, which was similar to photo B, but the deflection was greater. Photo D shows the cracking pattern for the synthetic polypropylene fiber, which shows a similar crack distribution as Figure $\mathrm{C}$.

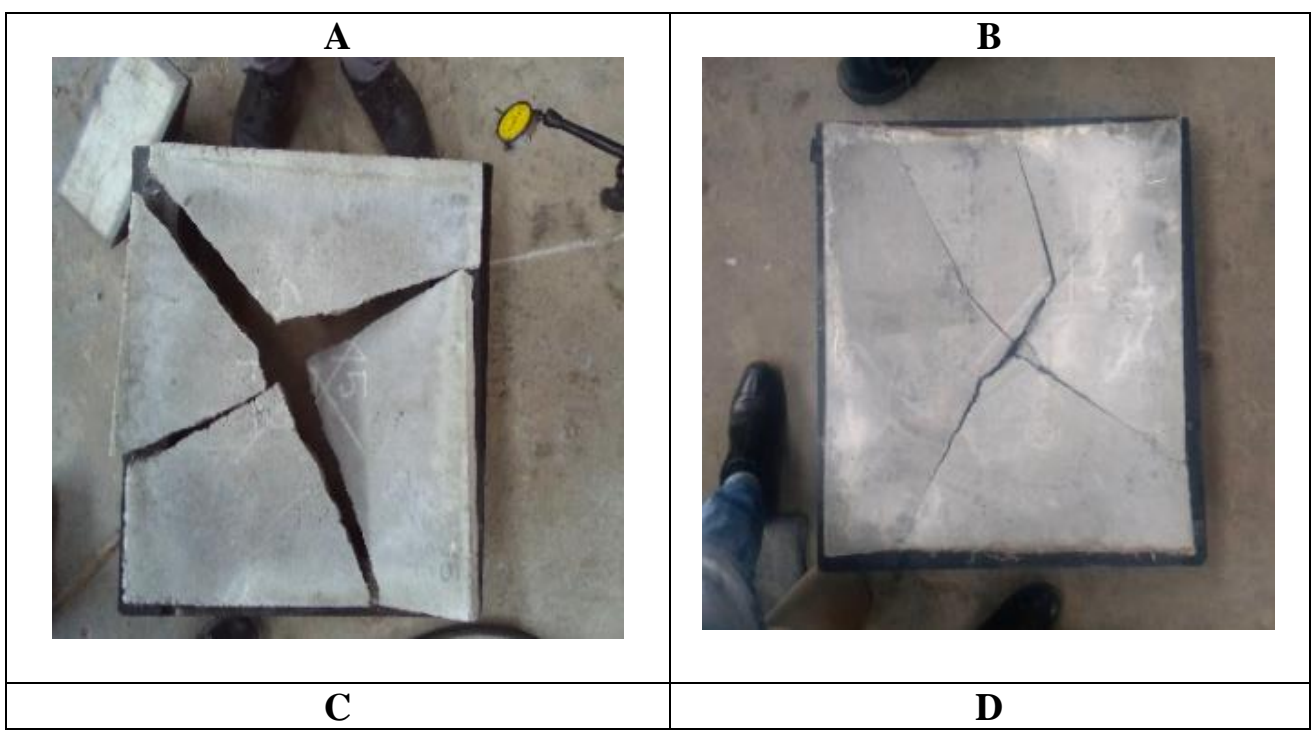




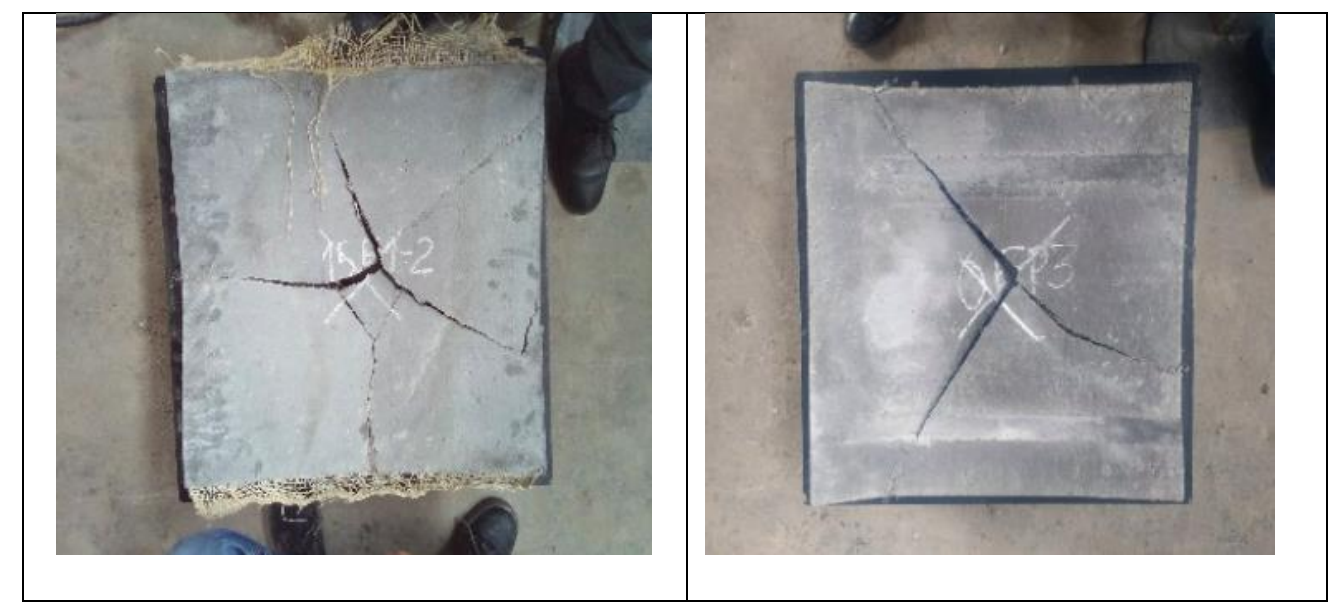

Figure 11. Cracking Pattern: A. Reference sample with no reinforcement; B. dense fiber sheets reinforcement; C. Standard fiber sheets reinforcement; D. synthetic polypropylene fiber reinforcement

\section{CONCLUSIONS}

This paper summarizes a preliminary research about the bending behavior of natural fiber sheets. The following conclusions were obtained from this part of the research.

- The use of fique fabrics as reinforcement of mortar sheets provides the material with an adequate flexural behavior, showing a remarkable increase in ductility and the capacity to store energy after cracking.

- Standard fabrics with a spacing of $2.5 \mathrm{~mm}$ showed a better behavior with respect to dense fabrics with a $0.2 \mathrm{~mm}$ spacing. This is due to the ability of the former to develop the interlocking component of the bonding stress.

- The behavior of the sheets reinforced with fique fabrics is comparable with that of the sheets reinforced with commercial polypropylene fibers. These natural materials generate great expectations for their use in construction materials.

- Fiber durability issues are of great importance. Although they were no included in this paper, they are an important aspect of the research project in which this paper is involved.

\section{ACKNOWLEDMENTS}

The authors acknowledge the support provided by Colciencias (funding 6172), and Universidad Nacional de Colombia (funding DIB 34835).

\section{REFERENCES}


[1] C. Elanchezhiana, B. Vijaya, Ramnathb, G. Ramakrishnanc, M. Rajendrakumard,V. Naveenkumare, M.K. Saravanakumarf. (2018). Review on mechanical properties of natural fiber composites. Materials Today: Proceedings 5 $1785-1790$

[2] Mohit Sood, Gaurav Dwivedi. (2017). Effect of fiber treatment on flexural properties of natural fiber reinforced composites: A review. Egypt. J. Petrol., https://doi.org/10.1016/j.ejpe.2017.11.005

[3] N. Saba, M. Jawaid, Othman Y. Alothman, M.T. Paridah. (2016). A review on dynamic mechanical properties of natural fiber reinforced polymer composites. Construction and Building Materials 106 149-159

[4] Obinna Onuaguluchi, Nemkumar Banthia. (2016). Plant-based natural fibre reinforced cement composites: A review. Cement and Concrete Composites 68 96e108

[5] Sanjay M.R., Suchart Siengchin, Jyotishkumar Parameswaranpillai, Mohammad Jawaid, Catalin Iulian Pruncu, Anish Khan. (2019). A comprehensive review of techniques for natural fibers as reinforcement in composites: Preparation, processing and characterization. Carbohydrate Polymers 207 108-121

[6] Miguel A. Hidalgo-Salazar, Juan P. Correa. (2018). Mechanical and thermal properties of biocomposites from nonwoven industrial Fique fiber mats with Epoxy Resin and Linear Low Density Polyethylene. Results in Physics 8 461-467

[7] S.A. Ovalle-Serranob, F.N. Gómeza, C. Blanco-Tiradob, M.Y. Combarizab. (2018). Isolation and characterization of cellulose nanofibrils from Colombian Fique decortication by-products. Carbohydrate Polymers 189 169-177

[8] L. J. Castellanos, C. Blanco-Tirado, J. P. Hinestroza, M. Y. Combariza. (2012). In situ synthesis of gold nanoparticles using fique natural fibers as template. Cellulose 19:1933-1943

[9] Gañán P, Mondragón I (2002) Surface modification of fique fibers. Effect on their physico-mechanical properties. Polym Compos 23(3):383-394

[10] S. Delvasto, E. F. Toro, F. Perdomo, R. Mejía de Gutiérrez. (2010). An appropriate vacuum technology for manufacture of corrugated fique fiber reinforced cementitious sheets. Construction and Building Materials, Volume 24, Issue 2, Pages 187-192

[11] G.H.D. Tonoli, S.F. Santos, H. Savastano Jr., S. Delvasto, R. Mejía de Gutiérrez, M. del M. Lopez de Murphy. (2011). Effects of natural weathering on microstructure and mineral composition of cementitious roofing tiles reinforced with fique fibre. Cement \& Concrete Composites 33 225-232 
[12] Leonidas Alexandros S. Kouris $\Uparrow$, Thanasis C. Triantafillou. (2018). State-of-theart on strengthening of masonry structures with textile reinforced mortar (TRM) Construction and Building Materials 188 1221-1233 